\title{
Developing and testing strategies for increasing awareness of the IUD as a contraceptive option
}

\author{
Ricardo Vernon \\ Population Council \\ M.E. Khan \\ Population Council \\ Harriet Birungi \\ Population Council \\ lan Askew \\ Population Council \\ William Stones
}

Follow this and additional works at: https://knowledgecommons.popcouncil.org/departments_sbsr-rh

Part of the Demography, Population, and Ecology Commons, International Public Health Commons, Public Health Education and Promotion Commons, and the Women's Health Commons

How does access to this work benefit you? Let us know!

\section{Recommended Citation}

Vernon, Ricardo, M.E. Khan, Harriet Birungi, lan Askew, and William Stones. 2007. "Developing and testing strategies for increasing awareness of the IUD as a contraceptive option," FRONTIERS Final Report. Washington, DC: Population Council. 


\title{
Developing and Testing Strategies for Increasing Awareness of the IUD as a Contraceptive Option
}

\author{
Frontiers in Reproductive Health Program, Population Council \\ Ricardo Vernon \\ M. E. Khan \\ Harriet Birungi \\ Ian Askew
}

Opportunities and Choices Programme, University of Southampton

William Stones

December 2007

\begin{abstract}
This study was made possible by the generous support of the American people through the United States Agency for International Development (USAID) under the terms of Cooperative Agreement No. HRN-A-00-98-00012-00 and Population Council In-house Project No. 5800 53071, and through the Opportunities and Choices programme of reproductive health research at the University of Southampton, funded by the Government of the United Kingdom Department for International Development. The contents are the responsibility of the FRONTIERS and Opportunities and Choices Programs and do not necessarily reflect the views of the sponsors.
\end{abstract}

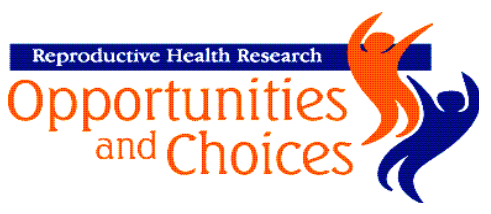

\section{(2) Population Council FRONTIERS}

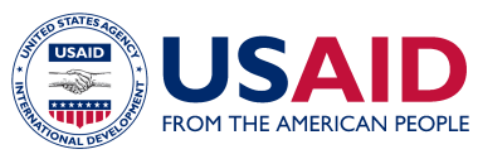




\section{CONTENTS}

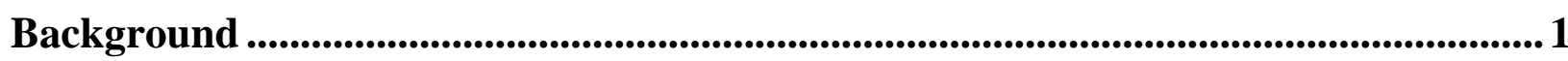

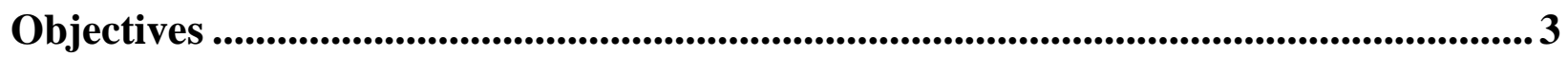

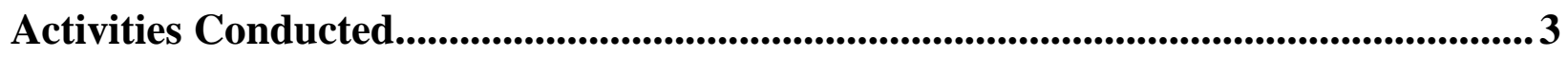

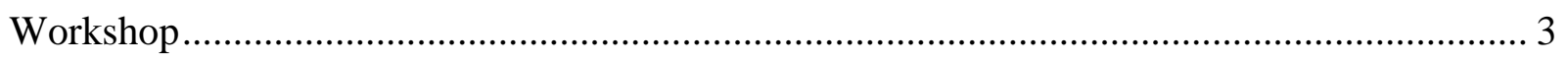

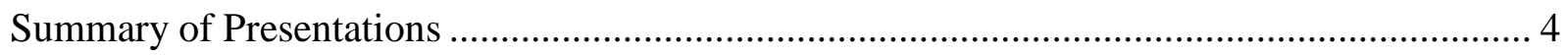

Summary of Proposal Outlines Developed......................................................................... 5

Development of Proposals and Implementation of Projects..................................................... 8

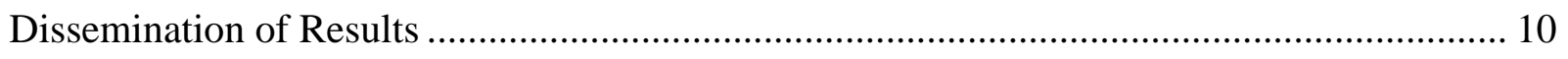

Appendices .......................................................................................................................................................... 11

Appendix 1: List of Participants at Southampton Workshop............................................... 11

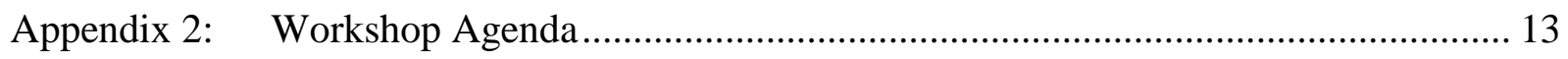

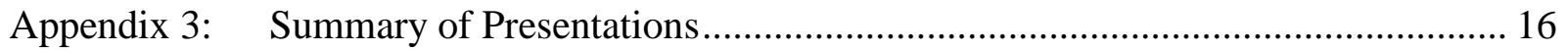




\section{BACKGROUND}

According to the Population Reference Bureau ${ }^{1}$, about 17\% (100 million) of all married women in less developed countries (LDCS) would prefer to avoid a pregnancy but are not using a contraceptive method. In Africa, 22 countries have levels of unmet need of 20 percent or higher, and in Latin America and Asia, most countries have levels of unmet need of 10 percent of women or higher. Unmet need can be distinguished between unmet need for contraception for spacing birth or for limiting births. Countries with low contraceptive prevalence rates usually have higher unmet need levels for spacing than for limiting births, whereas the opposite is usually true in countries with mid and high contraceptive prevalence rates. In general terms, women in rural areas, women over 30 years of age, and women from ethnic minorities have higher levels of unmet need than women in urban areas and younger women, and they are more likely to have unmet need for limiting than for spacing births.

The contraceptive prevalence rate in LDCs, excluding China, was estimated to be 49 percent in 2002 for all methods and 41 percent for all modern methods. The most widely used method in LDCs was sterilization, used by about 17 percent of all couples. Only about two percent used vasectomy. The most frequently used method for spacing births continues to be the pill (8\%), traditional methods $(7 \%)$, the injection $(5 \%)$, the IUD $(5 \%)$ and the condom $(3 \%)^{2}$. Surveys conducted in several countries over the last three years, however, have shown trends of rapidly increasing use of injectable contraceptives and condoms, and decreasing use of the IUD. An analysis by country shows that widespread use of the IUD is concentrated only in a few countries, such as Egypt, Tunisia, Mexico, Vietnam, North Korea and several former soviet republics. By region, the lowest use of the IUD is observed in Africa, where few countries show more than one or two percent use of the method.

The IUD is a very effective method: only one out of 125 women who use it during one year become pregnant. It also has a very long duration of use - at least 10 years. The method does not interfere with intercourse, it is immediately reversible, it can be used during lactation and during menopause, and it has very few side effects ${ }^{3}$. The IUD can be safely used by HIV-infected women, does not cause infertility, and can be safely provided to nulliparous women; it is also the most cost-effective method of reversible contraception, especially when protocols with few follow-up visits are established ${ }^{4}$. Trained personnel in most minimally equipped health facilities can provide IUD services. The method does not require constant re-supply, thereby reducing consequent costs of transportation and other opportunity costs. In rural settings, use of the IUD can address poor access to sterilization services for those wanting a long-term method and greatly increases the choice of women interested in spacing births.

1 Ashford, Lori. 2003. Unmet need for family planning: recent trends and their implications for programs. Policy Brief. Measure Communications, Population Reference Bureau, Washington D.C., March, pps. 1-8.

2 Population Reference Bureau. 2002. Family Planning Worldwide: 2002 Data Sheet, Washington D.D., PRB.

3 Hatcher, Robert; W. Rinehart, R. Blackburn and J.S. Geller. 1997. The Essentials of Contraceptive Technology. Population Information Program, Center for Communication Programs, Johns Hopkins School of Public Health. July.

4 FHI. Underused Research Findings. At: www.fhi.org/en/RH/Programs/RtoP/underusedres.htm 
Despite these many advantages, recent research gives some clues as to the reasons for low and declining use of the IUD in many parts of the world, as well as programmatic responses to address this problem. The Population Council's USAID-supported Frontiers in Reproductive Health (FRONTIERS) program, the University of Southampton's DFID-funded Opportunities and Choices programme, and FHI's USAID-funded Contraceptive Technology and Family Planning Research (CTFPR) Project have undertaken a number of activities that address this issue from different but related perspectives. These include:

- Studies in Guatemala and Honduras that demonstrate the safety and acceptability of training front-line paramedical staff to provide IUD services in rural areas (FRONTIERS).

- A study in Honduras to compare the effectiveness of alternative screening procedures for determining a woman's pregnancy status when she requests an IUD (FRONTIERS).

- A study in Honduras to test the effectiveness of a brochure describing the availability of the IUD and other reproductive health services in clinics where nurse auxiliaries have been trained (FRONTIERS).

- Studies in Ghana (FRONTIERS), Kenya (FHI) and Nepal (Opportunities and Choices) to assess the reasons for low and declining levels of use of the IUD.

- A study in Nepal to assess the acceptability and continuation of use of the IUD in rural areas (Opportunities and Choices).

- A study in China that reviewed the role of the IUD within the contraceptive method mix (Opportunities and Choices).

- A study in Kenya to re-introduce the IUD through a multi-faceted strategy by the MOH (CTFPR).

The factors identified through these studies are related to both the supply of and demand for the method. Among factors related to supply of IUDs are the following:

- A sufficiently large proportion of providers has not been trained in IUD insertion and removal techniques, or do not have confidence in their skills after training.

- Even when physicians or nurses in outpatient clinics have been trained, a large proportion of health facilities lack adequate equipment to routinely provide the method.

- Providers often do not mention the IUD during counseling sessions, and when they do, tend not to give complete information about it.

- A large proportion of providers believes the many incorrect rumors about the method, and admits to having negative attitude towards the method.

- Inappropriate criteria are often established to provide the method, such as minimum age and number of children, nutritional status, requiring menses, having a Pap test or requiring consent of the husband. 
The following factors relate to the demand side:

- A large proportion of women have not heard of the IUD, making it one of the least known contraceptive methods in several countries.

- Those women who have heard of the method often do not know its specific characteristics, such as its size, placement, duration, mode of use, and action mechanism.

- Many rumors exist about the method, many of which are believed to be true.

- Potential users often do not know where the method is available and believe the method is provided only at a high cost.

Much of the programmatic and research experience gained over the past two decades has focused on increasing understanding of supply-side factors that limit the provision and use of the IUD, for example, developing training programs, demonstrating the ability of lower level medical staff to provide the method, and assessing the interaction between IUDs, STIs and, more recently, HIV. There is now sufficient empirical evidence from a range of settings to allow program managers and technical assistance organizations to develop guidelines and plans for strengthening the systems necessary to support country-level introduction or 'rehabilitation' of the IUD within a program offering a range of contraceptive choices.

\section{OBJECTIVES}

- To conduct a meeting of researchers and program managers from three continents and several international organizations to review reasons for under-utilization of the IUD and recent experiences in increasing awareness about the IUD.

- To develop proposals for operations research projects to test the most promising interventions to introduce and expand access to IUD services and to implement the projects with national partner organizations.

- To disseminate results of the successful strategies.

\section{ACtivities ConduCted}

\section{Workshop}

A workshop was held in Southampton, England on $18^{\text {th }}-20^{\text {th }}$ February, 2004 to identify the most promising interventions for increasing access to the IUD and to generate protocols for small-scale operations research projects to be undertaken in selected countries. Participants were academics, policy makers, program staff and service providers from Bangladesh, Ghana, Guatemala, Honduras, India, Kenya and Nepal. Staff members from several international organizations participated, including the Opportunities and Choices Programme, University of Southampton, Population Council, FHI, EngenderHealth and Marie Stopes International. Appendix 1 lists the participants. 
The workshop objectives were to:

- Review international experiences with approaches to increase access to and use of the IUD.

- Identify factors explaining the decline in IUD use in many countries.

- Identify factors favoring client demand for IUD.

- Review barriers to effective IUD service delivery.

- Identify issues of access and equity in provision for poor and under-served groups.

- Prepare the basic elements for operations research protocols for operations research studies to address the factors identified.

Appendix 2 presents the workshop agenda. During the first day of the workshop, presentations and analysis of the factors affecting demand for and use of the IUD were made. The second day was devoted to discussing the key issues and questions that should be developed into operations research proposals. On the third day, participants prepared draft outlines of research proposals that would be completed after the workshop.

\section{Summary of Presentations}

The workshop was opened by Dr. William Stones, Director of the Opportunities and Choices Programme. Participants then made nine presentations of research projects that had sought to address and increase the availability and use of the IUD in different settings. Appendix 3 presents summaries of these presentations. Key issues presented included the following:

- Dr Sabu Padmadas presented an overview of contraceptive method mixes globally. Although IUD use has increased overall, this is because its use is highly concentrated in a few countries with large populations, mostly in Asia, but is little used elsewhere.

- Diagnostic studies in several countries (Ghana, Guatemala, Kenya and Nepal) have shown that fewer women know about the IUD than other modern contraceptive methods. Among those who do know of the IUD, most have misconceptions about the method and have little practical information regarding sources where it can be obtained and at what cost, its effectiveness and duration of use, and how it is used. In most countries (with the exception of Ghana), a substantial proportion of providers hold negative attitudes about the method, lack accurate information, and have incomplete training to be able to provide the method. With the exception of Ghana, most diagnostic studies found that most health facilities are poorly equipped and supplied to provide the method. These findings indicate the need to increase awareness about the method among potential users, to strengthen training of providers, and to improve the equipment and logistics for supplying health clinics.

- Several pilot projects have successfully demonstrated ways to increase accessibility to and availability of the IUD. Most have emphasized training of providers, including in family planning counseling, information, education and communication (IEC) and in IUD insertion and removal. All projects implemented IEC activities to increase awareness of the method and its availability in clinics, including through printed materials (flyers, brochures, and posters) in clinics and communities, interpersonal communications in clinics (talks in waiting 
rooms, and during consultations), and community activities (volunteer educators, and community health talks). In Nepal, radio messages were also used successfully, and in Kenya efforts were made to achieve consensus among advocacy partners such as professional associations, local and international NGOs, and health program managers.

- Paramedical service providers (including professional and auxiliary nurses) can be trained to provide safe IUD services. In Central American countries, however, a substantial proportion of those who start training do not complete it because of insufficient users, and many of those who do complete the training do not provide the IUD when they return to their clinics; clearly, alternative training and supervision strategies need to be developed.

- Appropriate counseling and use of IEC strategies can increase the demand for IUD services. However, little information about the cost-effectiveness of the strategies or its comparative advantage has been obtained. Dr. John Bratt reviewed issues around the economic evaluation of interventions to increase awareness, availability and accessibility of the IUD.

\section{Summary of Proposal Outlines Developed}

Participants were divided in three teams, each of which developed at least one outline for an OR project proposal that could later be finalized and submitted for funding. Although initially the intention was to have a common intervention and research design, the teams worked independently and the resulting outlines were substantially different. The draft outlines were presented to the group as a whole for review and discussion. All teams agreed to finish and finalize their proposals after the workshop and submit them for funding. Outlines of OR project proposals were developed for Bangladesh, Ghana, Guatemala, Honduras and Kenya.

Bangladesh: The participants from Bangladesh proposed to develop an intervention in coordination with the $\mathrm{MOH}$, Marie Stopes International and the Opportunities and Choices programme. The proposed interventions in rural areas included:

1. Re-orientation sessions on the IUD for District and Thana level service managers. Outputs would include numbers of attendees, the level and quality of participation at meetings, and documentation of concerns and responses;

2. Re-orientation sessions to counter myths and misconceptions about the IUD and to gain familiarity with IEC materials and their use for outreach workers and supervisors. Outputs would include numbers of attendees, a pre and post test, and subsequent follow up to assess retention of the material discussed. 
The proposed interventions for urban areas included:

1. Re-orientation sessions on the IUD, conceptualized as an 'IUD package of care' for clinic managers and supervisors. Outputs would include records of numbers of attendees, the level and quality of participation at meetings, and documentation of concerns and responses;

2. Technology updates and orientation about the use of IEC materials and the 'IUD package' would be arranged for mini-clinic service providers, paramedics and volunteers. Outputs would include numbers of attendees, a pre and post test of knowledge retention, documentation of concerns, and subsequent follow up to assess retention of the material discussed.

\begin{tabular}{|l|l|l|}
\hline \multicolumn{1}{|c|}{ Location } & \multicolumn{1}{|c|}{ Experimental } & \multicolumn{1}{c|}{ Control } \\
\hline Rural (MOH) & $\begin{array}{l}\text { One rural district with adverse poverty } \\
\text { indicators; two Thana selected within } \\
\text { the district }\end{array}$ & $\begin{array}{l}\text { Similar rural district; two Thanas } \\
\text { with similar socioeconomic } \\
\text { profile selected within the district }\end{array}$ \\
\hline Urban (MSI) & Slum area, 20-30,000 population & Similar slum areas \\
\hline Both & $\begin{array}{l}\text { 1. Specified minimum quality and access to services in each setting } \\
\text { 2. Similar socioeconomic conditions in control and experimental } \\
\text { settings }\end{array}$ \\
& 3. Similar clinic infrastructure \\
\hline
\end{tabular}

The primary outcome measures proposed for the study were:

1) Number of acceptors of intrauterine contraception

2) Number of women seeking intrauterine contraception but advised not to use the method following screening.

The secondary outcomes to be measured only in the experimental areas included:

1) Costs of the intervention

2) Socio-demographic characteristics of acceptors

3) Sources of information about the method as reported by clients

4) Continuation / discontinuation rates.

Guatemala and Honduras: Participants from Central America produced outlines for projects in Guatemala and Honduras that proposed to test a similar intervention. In both countries a facilitybased IEC strategy would be implemented, and in Guatemala the effects of a refresher posttraining course and of supervision visits would be tested.

In Honduras, participants proposed to assess the effects of facility-based activities to increase awareness in communities about the IUD. The project would be conducted in $\mathrm{MOH}$ facilities with the participation of EngenderHealth and the Population Council. The team proposed an experimental pretest/post-test design with a control group. Fourteen health sectors, each with an average of five health units, would be randomly assigned to the experimental or control group. In the experimental group, providers would be trained to conduct client and community level information activities and be provided with a set of materials to help them conduct these 
informational activities, including: 1) a manual for the promotion of reproductive health services, 2) an instructional flyer, 3) a brochure explaining the characteristics, advantages and disadvantages of the IUD, and 4) a letter-sized poster highlighting the key characteristics of the method and promoting the place that delivers the service (the flyer and the poster were based on the materials that had been used in Nepal). The dependent variables included the number of women that requested an IUD, the number of women that received an IUD, and the characteristics of women that received the method, as well as the cost per additional user generated by the strategy. To ensure that counseling and method choice procedures were not compromised by these information efforts, simulated clients would visit participating health centers and posts before and after the intervention.

In Guatemala, a pretest/posttest control group design was proposed. Ninety health districts with trained IUD providers and the appropriate equipment and supplies would be randomly assigned to three different groups: one where only the IEC activities would be conducted, one where IEC and follow-up on-site supervision would be conducted, and the control group that would continue providing services in a routine fashion. The IEC intervention was identical to the one proposed for Honduras. The post-training follow-up and supervision consisted of one half-day refresher session on the community IEC model after the training and between one and three visits by a supervisor to observe the trained service provider conduct at least three IUD insertions and/or removals in each visit in his or her own health unit with clients generated by the IEC activities.

The proposed variables were: the number of women requesting and receiving the IUD; reasons for not receiving the method; the characteristics of women receiving an IUD; the cost of implementing the community information strategy and post-training follow-up and supervision activities; and the quality of service provided to users, assessed by simulated clients using a checklist to report the quality of care received during counseling and by supervisors.

Ghana: Participants from Ghana proposed to train community health officers (CHOs) and community health volunteers (CHVs) in educational activities focused on creating a more informed awareness of, and interest in, long-acting contraceptives, and particularly the IUD. The trained CHOs would then be randomly assigned to two experimental groups, one in which clients would be referred to the nearest health center where the method desired was available, and one in which the $\mathrm{CHO}$ would be trained to provide IUD services in the health centers to which they are affiliated (CHOs are nurses who live and work in "community health compounds" built or renovated by the community. Community health volunteers assist the $\mathrm{CHO}$ to conduct activities). Districts included in the experiment had to already have the IUD available in facilities with trained staff and appropriate equipment, supplies and infection prevention equipment. The dependent variables would include the number of IUDs provided and the cost-effectiveness of the interventions. 


\section{Development of Proposals and Implementation of Projects}

In the months following the workshop, the country and regional teams sought to obtain commitment from the various stakeholders so as to be able to finish and submit the proposals. In some countries it was not possible to either complete the proposals or to obtain commitment from crucial stakeholders to be able to implement the project (as was the case with USAID in Guatemala). In Bangladesh, initial planning was undertaken by MSI but the large scale floods in that season seriously disrupted activities and it was not possible to take the project forward. Final proposals were submitted from India, Ghana and Honduras.

India: Given the obstacles to developing and implementing a project in Bangladesh, FRONTIERS staff assessed opportunities for conducting a project in other countries. The Directorate of Family Welfare and the Vadodara Municipal Corporation showed a strong interest in the project and developed and submitted a proposal at the beginning of 2006. The project is ongoing and will end in 2008. The interventions being tested include conducting a communitybased behavior change communications (BCC) campaign involving pharmacists, as well as private health providers, and enhancing accessibility to IUD services at the Community Health Centers (CHCs), Primary Health Centers (PHCs), and selected sub-centers and Reproductive and Child Health $(\mathrm{RCH})$ camps. Only providers certified by the government are providing the IUD services, which include counseling, insertion, removal and case management. As part of the project, their skills were strengthened through a refresher course. A cost analysis will also be conducted to assess the cost-effectiveness and economic viability of the interventions. A nonexperimental pre and post design with no control group is being used to measure the effect on key dependent variables that include the intention to offer and use the IUD, and the number of IUD acceptors in the study areas. Service statistics are being collected and pre and post surveys of 1,200 persons (600 each from rural and urban sites) will assess changes in knowledge, attitudes and behaviors regarding the IUD. A follow-up interview of 200 IUD acceptors (100 each from rural and urban areas) will be held between six and eight weeks after IUD insertion to assess the quality of counseling and services.

The formative research revealed a wide range of misconceptions among men and women regarding the IUD: that it causes cancer, increases the weight of women, causes a lot of pain, moves inside the body until it reaches the heart or brain, hurts men during intercourse, etc. The quantitative baseline showed that only $4.1 \%$ of women in the project area were using the IUD (and 59\% used any method), 23\% had not heard of the IUD (41\% among men), and less than $10 \%$ knew about its effectiveness, duration of protection against pregnancy and how the IUD works. Less than $75 \%$ of medical officers in health posts knew about the effectiveness of the method, when it can be inserted, when the first follow-up visit should be conducted, and whether it interferes with sex. Overall, $32 \%$ of health care providers were classified as having poor counseling skills, although most had a positive attitude towards the method.

Honduras: The final proposal matched very closely the outline that had been produced during the workshop in Southampton. An experimental pretest/post-test design with a control group was used to evaluate the impact of an IEC intervention. Forty-one health centers in 18 municipalities were randomly assigned to either the experimental or control group. In the experimental group, 
providers were trained in August 2005 to conduct client and community information activities, and provided with a set of four informational materials. Service statistics for the pre-intervention period (January to September 2005) and post-intervention periods (October 2005 to May 2006) were compared.

Data collected through simulated clients before and after the intervention showed that the IEC strategy did not bias delivery of family planning services generally, nor did it limit users' free and informed choice. Counseling post-intervention was found to be of a higher quality as a consequence of quality control reinforcement during training workshops. In the experimental group, the monthly average of IUDs delivered by the health center doubled from 1.12 to 2.0, whereas in the control group it decreased from 1.72 to 0.78 . Health centers that implemented the strategy with a high intensity increased their monthly averages by 1.27 IUDs, compared with an increase of 0.45 among those that implemented the strategy with low intensity. Clinic records show that the strategy attracted women who had fewer years of schooling and a greater number of children, who took longer to reach the health center, and who had never used a contraceptive method, compared with women in the control group.

Ghana: The Ghana Health Service (GHS), in collaboration with FRONTIERS and EngenderHealth, tested innovative approaches to increase awareness of the IUD and to improve access to the method. The strategies assumed that interpersonal communication tailored to community beliefs and fears about the method were likely to stimulate demand for long-term methods, including the IUD. The interventions consisted of: 1) giving information updates on long-term methods to the Community Health Officers (CHOs); 2) training CHOs and community volunteers to educate community members about long-term family planning methods (including the IUD) and assessing the community member's knowledge of, perceptions about, and intention to use long-term methods; and 3) training CHOs in IUD service delivery in zones where the educational interventions had been conducted. Dependent variables included changes in the knowledge, attitudes and perceptions of the CHOs and of community inhabitants, the demand for IUD services and the cost-effectiveness of the interventions.

Regions in Ghana were grouped according to whether they had an increasing or decreasing trend in IUD use in the period 1988-2003 according to DHS data. From each group one region was selected, and in each region one district with a fully functioning Community Health and Planning Services program (CHPS) was selected (Abura Asebu Kwamankese in Central region, Birim North in Eastern region, and Nkwanta in Volta region). Ideally, each intervention was supposed to be tested in six CHPS zones, with each district contributing two zones. However, this was not possible in the Nkwanta district; consequently, the study design had to be adjusted and 8 CHPS zones were included in one Intervention Group (refresher training for CHOs and volunteers, and community education) and compared with four CHPS zones in the second Intervention Group (the same activities plus training of CHOs in the delivery of IUD services); six zones were included to form the comparison group where no interventions were conducted.

Preliminary results show no significant changes in the knowledge of contraception among the communities in general, but a significantly higher knowledge of long-term methods, and the IUD in particular, in the two intervention groups but not in the comparison group. Further, the proportion of community residents that mentioned the $\mathrm{CHO}$ as a source of information also 
increased significantly. Providers showed a high level of knowledge of the IUD during the endline, including the duration of its effectiveness, how to check if the IUD is in place and counter-indications. Volunteers also had good knowledge, but almost no one mentioned CHOs as providers of the method.

The statistics kept by CHOs showed a significant increase in the number of new acceptors for all FP methods across all the study groups. Injectables continued to be the most popular method, however, there was also a distinctive increase in the uptake of the IUD and of the implant in the second intervention group (where insertions were done by the $\mathrm{CHO}$ at the community level).

\section{Dissemination of Results}

The third objective of this project is to disseminate the results. However, because at this point in time only one project has been finished, dissemination has occurred only within Honduras. As soon as the project results are available, an OR Program Brief and a peer-reviewed article will be prepared describing the experiences observed in the different OR projects for testing strategies to increase accessibility to IUD services. 


\section{APPENDICES}

\section{Appendix 1: $\quad$ List of Participants at Southampton Workshop}

\begin{tabular}{|c|c|c|}
\hline Name & Institution and Country & Address \\
\hline 1. John Pile & $\begin{array}{l}\text { Engender Health } \\
\text { USA }\end{array}$ & $\begin{array}{l}\text { mcharles@engenderhealth.org } \\
\text { i.pile@engenderhealth.org } \\
\text { Tel: } 12125618067\end{array}$ \\
\hline 2. Erin McGinn & Family Health International & $\begin{array}{l}\text { EMcGinn@fhi.org } \\
\text { Tel :1919544 7040/ } \\
19195447261\end{array}$ \\
\hline 3. John Bratt & $\begin{array}{l}\text { Family Health International } \\
\text { USA }\end{array}$ & Jbratt@fhi.org \\
\hline 4. Ivy Osei & $\begin{array}{l}\text { Health Research Unit } \\
\text { Ghana Health Service } \\
\text { Ghana }\end{array}$ & $\begin{array}{l}\text { angegaz50@yahoo.com } \\
\text { ivy.osei@hru-ghs.org }\end{array}$ \\
\hline 5. Pradhan Yashovardhan & $\begin{array}{l}\text { Ministry of Health } \\
\text { Director, Family Health Division } \\
\text { Government of Nepal }\end{array}$ & $\begin{array}{l}\text { Teku, P.O. Box } 820 \\
\text { Kathmandu } \\
\text { Nepal } \\
\text { fhd@wlink.com.np }\end{array}$ \\
\hline 6. Shabnam Shahnaz & $\begin{array}{l}\text { Marie Stopes International } \\
\text { Director - Asia } \\
\text { UK }\end{array}$ & $\begin{array}{l}\text { shabnam.shahnaz@mariestope } \\
\underline{\text { s.org.uk }}\end{array}$ \\
\hline 7. Yasmin Ahmed & $\begin{array}{l}\text { MSI Dhaka } \\
\text { Bangladesh }\end{array}$ & yasmin@mariestopesbd.org \\
\hline 8. Sally Kidsley & $\begin{array}{l}\text { Opportunities and Choices } \\
\text { Research Fellow } \\
\text { University of Southampton } \\
\text { Highfield, Southampton SO17 1BJ, } \\
\text { UK }\end{array}$ & $\frac{\text { sgk@soton.ac.uk }}{\text { Tel: 44-23-80 } 597988}$ \\
\hline 9. Will Stones & $\begin{array}{l}\text { Opportunities and Choices } \\
\text { Director } \\
\text { University of Southampton } \\
\text { Highfield, Southampton, SO17 1BJ } \\
\text { UK }\end{array}$ & $\frac{\text { r.w.stones@soton.ac.uk }}{\text { Tel: 44-23-80-59-5763 }}$ \\
\hline 10. Martin Rew & $\begin{array}{l}\text { Opportunities and Choices } \\
\text { Research Fellow } \\
\text { University of Southampton } \\
\text { Highfield, Southampton } \\
\text { SO17 1BJ, UK }\end{array}$ & $\frac{\text { M.Rew@soton.ac.uk }}{\text { Tel: 44-23-80-59-7988 }}$ \\
\hline 11. Sabu Padmadas & $\begin{array}{l}\text { University of Southampton } \\
\text { Teaching Fellow } \\
\text { University of Southampton } \\
\text { Highfield, Southampton SO17 1BJ } \\
\text { UK }\end{array}$ & $\frac{\text { ssp@socsci.soton.ac.uk }}{\text { Tel: } 44-23-80-59-4382}$ \\
\hline 12. M.E.Khan & $\begin{array}{l}\text { Population Council } \\
\text { India }\end{array}$ & $\begin{array}{l}\text { mekhan@pcindia.org } \\
\text { mekhan@popcouncil.org }\end{array}$ \\
\hline 13. Ricardo Vernon & $\begin{array}{l}\text { Population Council } \\
\text { Mexico }\end{array}$ & rvernon@popcouncil.org.mx \\
\hline
\end{tabular}




\begin{tabular}{|c|c|c|}
\hline Name & Institution and Country & Address \\
\hline 14. Ian Askew & $\begin{array}{l}\text { Population Council Regional Office } \\
\text { Frontiers in Reproductive Health }\end{array}$ & $\begin{array}{l}\text { General Accident House } \\
\text { Ralph Bunche Road } \\
\text { P O Box 17643 } \\
\text { Nairobi, Kenya } \\
\text { iaskew@pcnairobi.org } \\
\text { iaskew@popcouncil.org } \\
\text { Tel. 254-20-2713480 } \\
\text { Fax 254-20-2713479 }\end{array}$ \\
\hline 15. Gloria Quansah-Asare & $\begin{array}{l}\text { Reproductive and Child Health } \\
\text { Unit } \\
\text { Ghana Health Service } \\
\text { Ghana }\end{array}$ & $\frac{\text { angegaz50@yahoo.com }}{\text { gloasarel@hotmail.com }}$ \\
\hline 16. Jane Wickstrom & USAID & $\begin{array}{l}\text { Health \& Population Office } \\
\text { Accra, Ghana } \\
\text { jwickstrom@usaid.gov }\end{array}$ \\
\hline 17. Sarah Harbison & USAID, USA & SHarbison@usaid.gov \\
\hline 18. Josephine Kibaru & $\begin{array}{l}\text { Kenya } \mathrm{MOH} \\
\text { Kenya }\end{array}$ & iaskew@pcnairobi.org \\
\hline 19. Ndugga Maggwa & $\begin{array}{l}\text { Institute for Family Health } \\
\text { Regional Director } \\
\text { Family Health International } \\
\text { Nairobi, Kenya }\end{array}$ & $\begin{array}{l}\text { Bmaggwa@FHI.or.ke } \\
254-020-2713913 / 4 / 5 / 6 / 7 / 8 / 9 \\
245-020-2721360\end{array}$ \\
\hline 20. Jennifer Wesson & $\begin{array}{l}\text { Institute for Family Health } \\
\text { Senior Research Associate } \\
\text { Family Health International } \\
2224 \text { E NC54 } \\
\text { RTP } \\
\text { NC } 27713 \\
\text { USA }\end{array}$ & $\begin{array}{l}\text { Jwesson@fhi.org } \\
\text { Tel } 919544-7040 \text { ext } 373 \\
\text { Fax } 919544-7261\end{array}$ \\
\hline 21. Jorge Solórzano & $\begin{array}{l}\text { Salud Project, Calidad } \\
\text { Guatemala }\end{array}$ & $\frac{\text { jsgua05027@gmail.com }}{\text { iorasobe25@yahoo.com.mx }}$ \\
\hline 22. Edwin Montufar & $\begin{array}{l}\text { APROVIME } \\
\text { Guatemala }\end{array}$ & $\begin{array}{l}\text { e5montufar@hotmail.com } \\
\text { e5montufar@gmail.com }\end{array}$ \\
\hline 23. Ivo Flores & $\begin{array}{l}\text { Ministry of Health } \\
\text { Honduras }\end{array}$ & $\begin{array}{l}\text { ivo@honduras.quik.com } \\
\text { ivofloresflores@yahoo.com }\end{array}$ \\
\hline 24. Fatiha Terki & $\begin{array}{l}\text { Technical Knowledge \& Support } \\
\text { Division IPPF } \\
\text { Medical Advisor } \\
\text { UK }\end{array}$ & fterki@ippf.org \\
\hline 25. Sofie de Broe & University of Southampton & \\
\hline 26. Joanne Gleason & $\begin{array}{l}\text { Population Council } \\
\text { Administrator } \\
\text { Washington, DC, USA }\end{array}$ & Jgleason@pcdc.org \\
\hline
\end{tabular}




\section{Appendix 2: $\quad$ Workshop Agenda}

Wednesday $18^{\text {th }}$ February

Theme: reviewing population perspectives and experience of IUD provision

$8.30 \mathrm{am}$ : Welcome, introductions and agenda briefing: Dr William Stones (Southampton)

$8.40 \mathrm{am}$ A global overview of method mix, with special reference to:

- IUD contribution to the method mix in low, medium and high CPR countries

- The case of China

- Demographic implications of young mass sterilization in South Asia -Dr Sabu Padmadas, Southampton

$9.10 \mathrm{am}$ : Reinventing the IUD: an overview of recent initiatives and developments based on two recent FHI workshops. Dr Erin McGinn, FHI North Carolina

$09.40 \mathrm{am}$ : Why is IUD use so low? Presentations and discussion on reasons for low use in:

- Ghana (Dr Ivy Osei/ Dr Gloria Quansah-Asare)

- Guatemala (Dr Edwin Montufar, Jorge Solórzano)

- Kenya (Dr Ian Askew)

$11.00 \quad$ Coffee

11.30 What are our experiences with interventions to increase awareness? Presentation and discussion of case studies from:

- Kenya (Dr Josephine Kibaru)

- Honduras (Dr Ivo Flores/ Dr Ricardo Vernon)

- Nepal (Dr Sally Kidsley)

$1 \mathrm{pm} \quad$ Lunch

$2 \mathrm{pm}$ : Continue discussion of case studies of increasing awareness

$3.15 \mathrm{pm} \quad$ Tea

3.30pm Service delivery issues (coordinated by Dr Ricardo Vernon with input from MSI Bangladesh) covering:

- Provider training and confidence

- Lack of equipment

- Provider bias

- Inappropriate selection criteria

$5.00 \mathrm{pm} \quad$ Review of Day 1 and conclude

Dinner at leisure 


\section{Thursday $19^{\text {th }}$ February}

Theme: Can we generate a template for a 'generic' intervention?

08.30 am onwards

Drawing from the lessons of the day before, small-scale interventions will be developed that focus on rendering potential family planning clients in the clinic catchment areas aware of:

- The availability of a wider range of methods at selected clinics

- The characteristics and appropriate use of each method (and possibly other reproductive health services offered at the clinics)

Potential interventions to be considered may be community-level communication strategies focused on increasing the community's understanding about reproductive health, the role of family planning in contributing to improved reproductive health, and the contraceptive options that are available for women with different needs, depending on their personal situations.

For discussion 1: should we pay more attention to identifying strategies for increasing awareness of and interest in the method that service delivery outlets themselves can have under their direct control? These facility based strategies could include activities such as distribution of flyers and brochures through clinic clients and satisfied method users, systematically informing all women visiting the health facility about the service available, inclusion of this announcement in all contacts made by field workers, establishment of referral systems and assessment of other low-cost, low-effort informational channels.

Facility-based strategies, including community outreach, could be the core of the interventions to be tested because public health providers in most countries rarely have a budget for advertising in the mass media, and because method-specific advertising in electronic mass media is not allowed in some countries. However, the potential for mass media information campaigns in interventions will be a basis for discussion as some of the workshop participants have had experience of this approach.

For discussion 2: To what extent do supply side factors need to be a part of the interventions to be tested? Although decisions will be made to ensure that the interventions be as homogeneous conceptually, if not operationally, as possible, while allowing for the differences between the countries involved. Some issues that may be discussed include:

- Type of service delivery outlets to be included in the projects: those currently providing IUD services, currently not providing them, or both.

- If training new providers is needed, the protocols required (e.g. ethical considerations; duration of training; number of live practice insertions; who, how and where will the competence of the trained providers be certified; characteristics of trainers; where will the training of new IUD providers will be conducted.) Includes consideration of new FHI provider checklist (Jennifer Wesson)

- Type of outreach workers to be trained (if appropriate).

- Supervision frequency, mechanism, contents, job-aids, as well as referral networks.

- Mix of services.

- Cost-effectiveness and sustainability of strategies. 
For discussion 3: How should interventions be configured so as to engage under-served, poor and marginalized groups within facility catchment areas and more widely (given that in some settings clients travel quite long distances to access particular services)? Are there aspects specific to IUD or will a general strategy aiming to engage poor/ under-served groups be sufficient to reach them?

Coffee available from $10.30 \mathrm{am}$;

Lunch $1 \mathrm{pm}$

Tea $3.30 \mathrm{pm}$.

Thursday evening Workshop Dinner: HMS Warrior, Portsmouth Historic Dockyard (Hosted by the University of Southampton)

\section{Friday $20^{\text {th }}$ February}

Theme: Adaptations of the generic protocol for specific countries and settings.

\subsection{Briefing}

9 am Group work (coffee available from 10.30)

1 pm Lunch

2 pm Reporting back from groups

3.30 Tea

$4 \mathrm{pm}$ Review and future action agenda

5 pm Workshop concludes

Dinner at leisure 


\title{
Appendix 3: $\quad$ Summary of Presentations
}

\author{
Presentation 1: A global overview of method mix \\ Dr. Sabu Padmadas gave an overview of trends in contraceptive method mixes in the world, the \\ characteristics of IUD method users, the factors affecting choice of the IUD (level of personal \\ knowledge gathered from peers, accessibility, availability and acceptance) and the factors \\ affecting use-continuity of the method (knowledge and presence of side-effects). The strategies \\ he suggested for improving IUD use were addressing the negative effects of the method, \\ appropriate provider training, assured pre-counseling and follow-up measures, safe-guarding \\ ethics and highlighting the importance of dual method. Other measures are involvement of men, \\ focus on unmarried adolescents, innovative market strategies, role model marketing and research \\ and monitoring.
}

\section{Presentation 2: An overview of recent initiatives and developments}

Dr. Erin McGinn of Family Health International sought to identify specific, actionable activities among RH organizations to advance provision of and increase client access to the IUD and to identify gaps in knowledge and additional research needed to address barriers to IUD access and use. She identified the need for: 1) developing and testing an IUD advocacy kit;2) determine how to address barriers to IUD provision at the provider level in existing projects and activities; and 3) harmonize and update training materials; 4) distill what has been learned in IUD diagnostic studies; 5) draft a programming guide for long-term methods and field test it in a few countries; 6) to develop guidelines for policy makers and framing IUDs in the context of contraceptive security; 7) increase awareness of the IUD as a contraceptive option for HIVpositive women among policy makers and program managers.

\section{Presentation 3: Diagnostic study in Ghana}

Dr Ivy Osei and Dr Gloria Quansah-Asare presented the results of a diagnostic study that sought to explain why IUD use is so low in Ghana (it has been stagnant at 1\% over a period of ten years, according to the 1998 Ghana Demographic and Health Survey). The study showed a limited knowledge about the IUD among clients compared to other methods. Fear and misperceptions about the method were widespread. However, most providers had a positive attitude towards the method ( 28 out of 35 providers would recommend the IUD to their friends while 18 out of 35 would use it themselves). The main fear of the provider was perforation of the uterus (24/35) and not acquisition of infection. The reasons suggested for low use of the IUD include poor product image and misconceptions, poor infrastructure for IUD services and risk of HIV infection to both client and provider, lack of promotion of the method. Other results showed that information exchanged between provider and client was good: they always asked the client for their method preference, $75 \%$ of the providers mentioned the IUD in counseling session and more than 50\% gave information on advantages and disadvantages of the method. Supplies and equipment needed to provide the service were available in over $90 \%$ of the health centers. However, out of 35 trained staff, 15 had not done any insertions in previous year due to low demand of the product. The barriers identified included rumors \& misconceptions, product design, side effects, insufficient promotion, insufficient providers with practical experience and complexity of service provision. 


\section{Presentation 4: The Experience in Guatemala}

Drs Edwin Montufar and Jorge Solórzano presented results of a diagnostic study and of an operations research study on increasing access to the IUD in Guatemala. Only 2.2\% of women in Guatemala use the IUD, and most of these in urban areas. The study showed that more than a half of the providers were misinformed about side-effects caused by the IUDs and $29 \%$ about counter indications. Although 53\% had received some IUD insertion training, only 15\% had inserted IUD under supervision in actual clients. Women also had little knowledge of the method and of the sources where they could get it, the costs of the method and its effectiveness. They mentioned 15 different rumors they believed in.

In the OR study an intervention was tested to train nurses and nurse auxiliaries in health centers and posts in a two-day in-group theoretical training, followed by on-site training with clients identified by the trainees. A minimum of five supervised insertions needed to e accomplished to complete training (i.e., achieve certification). Each district selected its own strategies for IEC; examples included distribution of brochures and fliers, making radio announcements, including the IUD in FP counseling, mentioning its availability in all contacts with women of reproductive age and asking satisfied users to present their experience in health talks at health center. Of 16 nurses and 36 auxiliaries that began theoretical training, 45 successfully completed training; in eight months they provided the method to 301 women. Lessons learned included the need for a strong training in management of STIs and complications needed and in decontamination procedures; the need to strengthen IEC activities; the need to identify trainers in communities.

\section{Presentation 5: The situation in Kenya}

Dr. Ndugga Maggwa discussed the reasons for low IUD use in Kenya, where its prevalence has decreased from 13\% in 1987 to 2.4\% in 2003 (KDHS). The reasons for poor IUD use in Kenya include concerns about safety, IUD service delivery, provider attitudes, logistics and supplies, training and policy. Safety of the IUD revolves around fear of increased risk of HIV/AIDS, risk of STIs and complications among HIV+ individuals. Some people fear infertility while others believe in myths and rumors again IUD. There are several issues in service delivery that need to be addressed. Firstly, the IUD is not talked about as much as other methods. Another problem is that rumors are not spontaneously discussed and benefits of IUD are rarely discussed during counseling. The counseling and IUD insertion takes time and providers are not motivated. The IUDs are available but expendables are inadequate. Appropriate equipment and speculums are not available. The state of facilities is not optimal for privacy required for counseling, insertion and removal. Lastly, it is difficult to achieve levels of infection control required for IUD insertion and removal. Many providers also have negative attitudes and poor training. On policy and guidelines issues, they lag behind scientific evidence (only women who have delivered one or more times are eligible for IUD; the method should not be used after 6 weeks post partum if client has not resumed menses; physical/pelvic examination is mandated in clinical settings to rule out pregnancy; only women menstruating are provided the method), they are not user friendly and they are little known by providers. Key recommendations were to improve auditory and visual privacy, improve training of providers (in infection prevention procedures, attitudes, knowledge of side-effects) and ensure that expendable supplies and equipment are available. Pre-service training should be emphasized and In-service training and practice for service providers is needed. Certification procedures need to be reviewed to support decentralized training. Regular and timely reviews of policies and guidelines are required to keep up with new 
information. Effective dissemination strategies for the guidelines should also be developed and the format of service provider guidelines should be made more user-friendly

\section{Presentation 6: Reintroduction of the IUD in Kenya}

Dr. Josephine Kibaru described an IUD Re-introduction initiative in Kenya to increase support for the method among policy makers and health care professionals and clients, increase the provision of quality IUD services and enhance demand for IUDs. The re-introduction process was in three steps: 1) issues identification, in which studies were conducted and results disseminated; 2) development of a program in which a task force developed a strategy; and 3) consensus building with identification of advocacy partners, development of advocacy briefs, and launch of the strategy and sensitization meetings. The advocacy partners involved professional associations and both local and international NGOs. Sensitization meetings involved provincial and district medical officers/health program managers. Lessons learned included the importance of building consensus right from the onset, using available IEC materials rather than developing new ones and the crucial role of $\mathrm{MOH}$ leadership.

\section{Presentation 7: The Experience in Honduras}

Dr. Ivo Flores, from the MOH in Honduras, presented results from four studies. The first study tested whether nurse auxiliaries could safely insert IUDs and provide Depo Provera and Pap smears. Sixty nurse auxiliaries, 23 nurses and 11 physicians were trained in 16 districts. 2,030 IUDs were inserted in one year, with only 3 pregnancies. The cost per new IUD user varied between $\$ 2.90$ and $\$ 18.60$ per district. The training model included theoretical training in a group and individualized practical training in high volume clinics. Certification was achieved by demonstrating proficiency during training (observation by means of checklist). Follow-up supervision in their clinics by nurse supervisors using a checklist was not very frequent in practice.

In a second study, 183 nurse auxiliaries, 56 professional nurses and 24 physicians started training and the proportion certified was $62 \%$ for nurse auxiliaries, $89 \%$ for professional nurses and $100 \%$ physicians. The main reason for non-certification was not having enough users demanding services at training centers to conduct supervised practices. The results showed that nurse auxiliaries cared for a monthly average of 7.3 new FP users (2.2 pills, 0.6 IUD, 3.7 injectable and 0.8 condoms) and took 5.2 Pap smears. If these results were extrapolated to the 867 health posts in the country, a total of 3,300 new IUD users and 36,500 new injectable users would be obtained. Only 58\% of the certified auxiliaries working in rural health posts reported having inserted an IUD after the training, compared to over $80 \%$ who provided Pap smears and Depo Provera services. The recommendations were to increase the proportion of nurse auxiliaries who are certified to insert IUDs by the end of their training by selecting participants more carefully, and ensuring that training is carried out in places with a sufficient volume of insertions. To increase the proportion of nurse auxiliaries who perform insertions when they return to their worksites by requiring them to identify IUD candidates before training, and carrying out the first insertions in their worksites under supervision. There was also a need for more frequent supervisory visits and conducting promotional activities before, during and after supervisory visits. Uncomplicated, low-cost promotional strategies need to be implemented. 
The results of a small educational study conducted in 2001 were also presented. Its objective was to see if a brochure offering IUD, Depo-Provera and Pap services increased the demand for these services in rural health posts. The intervention involved the nurse auxiliaries giving 10 minute talks and asking participants to distribute the brochures among friends. Twelve health posts were randomly assigned, 6 in the experimental group (where brochures were distributed) and 6 in the control group (where no activity was conducted.) The results showed that IUD insertions increased from 2.8 to 4.5 per month in the experimental group, while they decreased from 1.4 to 0.9 in the control group. Use of Depo-Provera increased by 1.8 users per month in the experimental group, and by 0.6 users in the control group. The pap smears increased by 1.6 samples per month in the experimental group, and decreased by 0.1 in the control group.

Finally, the results of an evaluation of performance and quality of services provided by nurse auxiliaries conducted by the $\mathrm{MOH}$ and EngenderHealth were presented. The objectives of the evaluation were to determine factors influencing IUD insertions by nurse auxiliaries, determine user perceptions of contraceptive methods, especially the IUD and Depo Provera, identify the perceptions of managers and providers of IUD insertions by nurse auxiliaries, and identify strategies to improve IUD services. In-depth interviews and focus group discussions were carried out with 3 regional directors and 20 regional, area and sector chief nurses in regions, 43 family planning users and 20 nurse auxiliaries that insert IUDs. The regions were the ones where EngenderHealth has conducted IUD insertion training. The results showed that the factors that influence conducting IUD insertions include liking the activity, referrals from community volunteer health workers, referrals from other clients, IUD promotion activities and good counseling. All users were satisfied with reproductive health services received. Regarding their opinions of the IUD, they said that it causes cancer, it gets stuck inside, it produces too much bleeding and women get pregnant. About Depo Provera, they said that it causes headaches, women do not see their menstruation, women get fat and others get thin and they make damage when breastfeeding as milk is not produced. Program managers think training nurse auxiliaries in IUD insertion is good because it helps increase the capacity to respond to the demand by users. The recommendations of the study were to improve supervision and logistic supply systems, promote the IUD by mentioning advantages, tolerance to it and long duration, increase the number of certified nurse auxiliaries and have ready the places where practice will take place and train small groups

Presentation 8: Promoting intrauterine contraception in Nepal: Action Research Dr Sally Kidsley presented the results of a study to increase access to the IUD in Nepal, where the IUD was the most popular and widely used method in 1966 with $98 \%$ of the total new acceptors, after which there was a sharp decline in use and $0.1-0.3 \%$ of married women have used the IUD between 1976 and 2001. FGDs in three districts showed that barriers preventing use of the IUD included lack of knowledge about the method, myths and rumors, poor accessibility and availability, and lack of husband involvement. Perceptions of positive aspects of IUD were that it is hassle/worry free, no requirement for operation, safe and reliable, no need to remember daily or every three months and it has no hormonal effects. The intervention in the study included awareness raising by means of radio, posters and female community health volunteers. There was a 60 second sketch broadcast on a daily basis in the three districts for two months. Five thousand culturally sensitive and adapted posters were distributed widely through 
the three districts. Female Community Health Volunteers were chosen from the bank of SPN promoters, and two days intensive training on the IUD was given.

Three nurses in three clinics were trained in the delivery of IUD services. The results showed that the campaign and its messages had been very well received. Of 333 clients that had the IUD inserted, 25 had the IUD removed, two had it reinserted, there were two expulsions and no pregnancies were reported. Sixty-nine percent of clients were followed-up. The 12-month follow-up questionnaire revealed that $81 \%$ of the clients had no problems with the IUD. 99\% stated follow up was important to them, $96 \%$ said they would recommend the IUD to others. The limitations of the study were that incentives were given to the promoters. The IUD was offered free of charge.

The policy implications were that the IUD is highly acceptable in the three districts of Nepal and the intervention strategies were effective in increasing the number of new acceptors. In order to maintain an increase in the marketing strategies must be in place for a longer period of time. Nurses were the most cost-effective method of marketing, but radio reached a wider audience. Female providers are important as male providers are potential barriers to uptake. The involvement of men in decision making is essential. The provision of follow up is vitally important. Thorough counseling ensures switching of methods if IUD discontinued. The experience of side effects in a negative predictor of continued use - thorough post insertion counseling may increase continuance. The use of analgesia for pain may increase continuance.

\section{PRESENTATION 9: Economic evaluation of interventions to increase awareness of the IUD}

The last presentation was made by Dr. John H. Bratt of FRONTIERS. He said there is a need to encourage effective use of limited resources and to inform decisions about bringing interventions to scale. The Frontiers approach is to focus on intervention phases and activities. The planning phase involves design/implementation of formative research and design of interventions (development of training curricula, job aids and IEC materials, training of trainers, establishing supervision schedules). The second phase is implementing the intervention which involves training of service providers (clinicians, fieldworkers) and production of IEC materials and job aids. The third phase is the service delivery, supervision and monitoring. It involves extra provider time and additional supervisory visits as needed.

He presented a model for estimation of costs involving inputs, processes and outputs. The inputs are equipment, labor and materials. The processes are planning, implementation, service delivery, supervision and monitoring. Outputs are process outputs that include supervision, training and planning, and service outputs that include clinic visits, visits to other facilities. The FRONTIERS approach to economic data collection is to focus on increment costs and prospective data collection. Incremental costs include costs that are incurred because of the intervention and include both monetary and non-monetary costs. Prospective data collection includes spreadsheet-based forms and requires regular updating by providers and study staff. However, there are issues of staff turnover/lack of continuity/sporadic TA. There is uneven local buy-in to the economic analysis seen as "add-in". 
Proposed modifications are to continue a focus on incremental costs, blend retrospective / prospective data collection and keep in touch. Blending the retrospective and prospective methods involves better dialogue at outset of study, building on information systems already in use and using simple forms to supplement.

Lessons learnt are that an OR intervention usually is more costly per unit than the scaled-up version. Scaling-up is not a simple multiplier. Just because the scaled-up version of the intervention is usually less costly does not make it feasible or affordable. Therefore if research is to become practice, we should design OR interventions with affordability and feasibility as key considerations. We can encourage affordability and feasibility by consulting with end-users and by building interventions on existing systems. But even an affordable and feasible intervention may be a poor use of scarce resources. 